\title{
Vibrational Characteristics of Four Wood Species Commonly Used in Wood Products
}

\author{
Wengang $\mathrm{Hu},{ }^{\mathrm{a}, \mathrm{b}}, *$ Shuang $\mathrm{Li}^{\mathrm{b}},{ }^{\text {and }}$ Yan Liu ${ }^{\mathrm{b}}$ \\ The effects of the moisture content, density, and striking direction of a \\ hammer on the vibrational characteristics, i.e., the fundamental frequency \\ and dynamic modulus of elasticity, of four wood species, i.e., poplar \\ (Populus tomentosa), mahogany (Swietenia mahagoni), beech (Fagus \\ orientalis), and ash (Fraxinus excelsior), commonly used in wood products \\ were investigated, aiming to provide basic evidence for the nondestructive \\ testing of wood materials. The results showed that the effect of the wood \\ species on the fundamental frequency, dynamic modulus of elasticity, and \\ static modulus of elasticity was statistically significant. The dynamic moduli \\ of elasticity of the four wood species were higher than the corresponding \\ static moduli of elasticity. The effect of the striking direction on the dynamic \\ modulus of elasticity was not significant, indicating that no matter where \\ the hammer struck, i.e., radial and tangential surfaces, the fundamental \\ frequency was essentially constant. Negative relationships were found \\ between the fundamental frequency and the density and moisture when \\ the data of the four wood species were viewed as a population sample. \\ The vibrational characteristics of each wood species varied, which can be \\ applied to the nondestructive testing of wood.
}

Keywords: Wood species; Fundamental frequency; Dynamic moduli of elasticity; Striking direction

Contact information: a: Co-Innovation Center of Efficient Processing and Utilization of Forest Resources, Nanjing Forestry University, Nanjing 210037 China; b: Department of Furniture Design, Nanjing Forestry University, Nanjing 210037 China; *Corresponding author: hwg@njfu.edu.cn

\section{INTRODUCTION}

Non-destructive testing (NDT) techniques based on acoustics have been studied for nearly half a century in the field of wood and wood-based materials. These techniques include determining the physical and mechanical properties of wood, as well as grading, drying, and detecting defects of wood. In addition, NDT has been widely used in wood engineering and wood constructions (Kawamoto and Williams 2002; Ju et al. 2019; Liu et al. 2019; Zhao et al. 2019; Zhou et al. 2019). Commonly used NDT techniques include, but are not limited to, stress wave method, mechanical stress deformation method, vibration method, acoustic emission method, etc. (Lv et al. 2018; Xu et al. 2020; Fu et al. 2021a; Yang and Liu 2021). The scale of tested wood samples can range from non-defective small samples to full-sized wood panels (Ilic 2003; Jiang et al. 2008; Katalin et al. 2014; Turkot et al. 2020; Tu et al. 2020; Fu et al. 2021b; Zhang et al. 2021). Studies researching the relationship between the dynamic modulus of elastic $\left(\mathrm{MOE}_{\mathrm{d}}\right)$ and the static modulus of elastic $\left(\mathrm{MOE}_{\mathrm{s}}\right)$ have primarily used the transverse vibration method, the vertical vibration method, the ultrasonic wave method, the stress wave method, etc. (Mohammad and Mohsen 2017; Bi et al. 2020; Zhao et al. 2020; Fu et al. 2021). Previous studies showed that correlation between the $\mathrm{MOE}_{\mathrm{d}}$ and $\mathrm{MOE}_{\mathrm{s}}$ was relatively higher when using the transverse vibration method compared to other methods (Bi et al. 2020; Fu et al. 2021). In 
addition, the $\mathrm{MOE}_{\mathrm{d}}$ decreased as the moisture content (MC) increased when $\mathrm{MC}$ of wood samples were below the fiber saturation point, and the fundamental frequency showed the same trend as the $\mathrm{MOE}_{\mathrm{d}}$ (Lu et al. 2016; Cai et al. 2020). The correlation of fundamental frequency with damping factor was negatively significant, while it was positively significant with $\mathrm{MOE}_{\mathrm{s}}$ and acoustic conversion efficiency (Olaoye et al. 2020). In addition, wood density had a correlation of 0.73 and 0.50 with $\mathrm{MOE}_{\mathrm{d}}$ and $\mathrm{MOE}_{\mathrm{s}}$ respectively (Olaoye and Okon-Akan 2020). However, although many studies have been performed, the fundamental vibrational characteristics and their relationships are still not clear, e.g., the relationships between the density and fundamental frequency and the MOEd.

In this study, the vibrational characteristics of four wood species commonly used in wood products were studied using the transverse vibration method based on fast Fourier transform (FFT) algorithms. Specifically, the effects of the density, moisture content, and striking direction of the hammer on the $\mathrm{MOE}_{\mathrm{d}}$ were studied and analyzed. Finally, the $\mathrm{MOE}_{\mathrm{d}}$ and $\mathrm{MOE}_{\mathrm{s}}$ of the four wood species were compared.

\section{EXPERIMENTAL}

\section{Wood Materials and Equipment}

Four commonly used wood species, i.e., poplar (Populus tomentosa), mahogany (Swietenia mahagoni), beech (Fagus orientalis), and ash (Fraxinus excelsior), were used in this study. The commercial wood lumbers were bought from a local supplier (Nanjing, China) and stored in a conditioning room longer than 1 year. The primary testing equipment used in this study included a universal testing machine (AG-X 20kN, Shimadzu, Kyoto, Japan) and its affiliated clamps and a FFT analyzer (F9000, Ono Sokki, Yokohama, Japan) and its specially designed microphone (MI-1235, Ono Sokki, Yokohama, Japan).

\section{Specimens Preparation}

The dimensions of the full-size lumber were $3000 \mathrm{~mm} \times 350 \mathrm{~mm} \times 50 \mathrm{~mm}$ (length $\times$ width $\times$ thickness). Twelve non-defective small samples measuring $300 \mathrm{~mm} \times 20 \mathrm{~mm} \times$ $20 \mathrm{~mm}$ were cut for each wood species according to GB/T standard 1936.2 (2009). For the ash and beech wood samples, grains in the transverse section were clear and straight, but it was difficult to distinguish the wood grains for the other two wood species.

\section{Testing Methods}

Figure 1 shows the setup for measuring the vibrational characteristics of the four wood species using the transverse vibration method based on FFT algorithms. The sample was hung on a wood framework via rubber bands, and the two hanging points were 0.224 times the sample length away from the two ends of the sample according to GB/T standard 1936.2 (2009) and ASTM standard D6874 (2020). The microphone used to receive signals was fixed upon the sample at a distance in $\mathrm{mm}$. The settings of the FFT analyzer were as follows: a sample frequency of 0 to $4 \mathrm{kHz}$, a sample point of 2018, and the threshold of microphone was $1 \mathrm{~Pa}$ to filter environmental noise. The testing method involved striking the right end of the sample with a professional hammer at a point $20 \mathrm{~mm}$ away from the right end and the signals were received by the microphone at the other side. One must be trained before formal testing can occur in order to keep the hammer force large enough to trigger the threshold. Five replications were repeated for each sample, and 12 samples were prepared for each wood species. In addition, the ash and beech wood samples were struck 
at both their radial and tangential surfaces. The dynamic modulus of elasticity $\left(\mathrm{MOE}_{\mathrm{d}}\right)$ was calculated by Eq. 1,

$$
E_{\mathrm{d}}=0.9464 l^{4} p f^{2} / h^{2}
$$

where $E_{\mathrm{d}}$ is the dynamic modulus of elasticity $\left(\mathrm{N} / \mathrm{mm}^{2}\right), l$ is the length of the sample $(\mathrm{mm})$, $p$ is air dry density $\left(\mathrm{g} / \mathrm{cm}^{3}\right), f$ is the fundamental frequency $(\mathrm{Hz})$, and $h$ is the height of the sample (mm) (Tao et al. 2019). After the transverse vibration tests, the samples were reused to conduct a three-point bending test to calculate the static modulus of elasticity (according to ISO standard 16978 (2003)), and the modulus of rupture (MOR) (according to GB/T standard 1936.1 (2009)). The loading rate of the testing machine was $5 \mathrm{~mm} / \mathrm{min}$, and the $\mathrm{MOE}_{\mathrm{s}}$ was calculated according to Eq. 2,

$$
E_{\mathrm{s}}=\Delta P l^{3} /\left(4 \Delta f b h^{2}\right)
$$

where $E_{s}$ is the static modulus of elasticity $\left(\mathrm{N} / \mathrm{mm}^{2}\right), \Delta P$ is the change of load in elastic stage of three-point bending test $(\mathrm{N}), \Delta f$ is the deflection corresponding to $\Delta P(\mathrm{~mm})$, and $b$ is the width of the sample (mm); the MOR was calculated according to Eq. 3,

$$
\sigma=3 P_{\max } l / 2 b h^{2}
$$

where $\sigma$ is the modulus of rupture $(\mathrm{MPa})$ and $P_{\max }$ is the maximum bending capacity $(\mathrm{N})$.

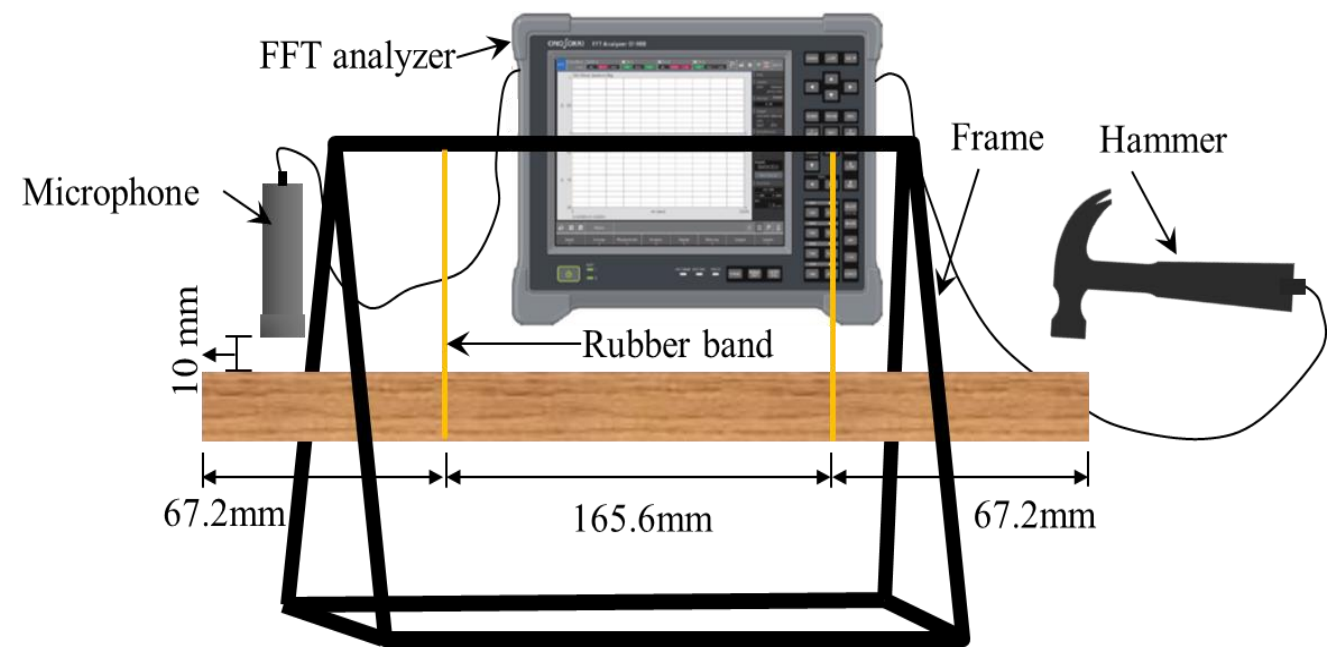

Fig. 1. The setup for measuring the vibrational characteristics of wood

Non-defective small samples (measuring $20 \mathrm{~mm} \times 20 \mathrm{~mm} \times 20 \mathrm{~mm}$ ) were cut from the ends of tested samples in order to measure the density, air dried density, moisture content (MC), volume shrinkage coefficient $(\mathrm{K})$, and density at $12 \% \mathrm{MC}\left(p_{12} \%\right)$, according to GB/T standard 1931 (2009) and GB/T standard 1933 (2009). The $\mathrm{K}$ and $p_{12} \%$ were calculated according to Eqs. 4 and 5, respectively,

$$
\begin{aligned}
& K=\left(V_{\mathrm{w}}-V_{0}\right) /\left(V_{0} \times W\right) \times 100 \% \\
& p_{12 \%}=p_{\mathrm{w}}[(1-0.01(1-K)(W-12 \%)]
\end{aligned}
$$

where $K$ is the volume shrinkage coefficient $(\%), V_{\mathrm{w}}$ is the volume of the sample at air dry conditions $\left(\mathrm{cm}^{3}\right), V_{0}$ is the volume of the sample at oven dry conditions $\left(\mathrm{cm}^{3}\right), W$ is moisture content in air dry condition, $p_{12} \%$ is the density of the sample at a moisture content of $12 \%$ $\left(\mathrm{g} / \mathrm{cm}^{3}\right)$, and $p_{\mathrm{w}}$ is the density of the sample at air dry conditions $\left(\mathrm{g} / \mathrm{cm}^{3}\right)$. 


\section{Statistical Analysis}

The effect of the wood species on the fundamental frequency $\left(F_{1}\right), \mathrm{MOE}_{\mathrm{d}}$, and $\mathrm{MOE}_{\mathrm{s}}$ was analyzed using analysis of variation (ANOVA) with a general linear model. Mean comparisons were conducted using the least significant difference (LSD) method if significance existed between the four wood species. The above statistical analysis methods were conducted using SPSS v22.0 (IBM, Armonk, NY) at a 5\% significance level.

\section{RESULTS AND DISCUSSION}

\section{Density and Moisture Content of the Evaluated Wood Species}

Table 1 shows that the air-dry density and MC of the four wood species were significantly different. The order of the air-dry density and MC from high to low is as follows: ash, beech, mahogany, and poplar. In addition, the MCs of the beech and mahogany samples were not significantly different. Since density is dependent on the MC, Eqs. 2 and 3 were adopted to transfer the densities of all wood species to the same MC, i.e., $p_{12 \%}$. Table 2 shows that the order of $p_{12} \%$ from high to low is as follows: ash, beech, mahogany, and poplar. This was convenient for further comparing the vibrational characteristics of the four wood species.

Table 1. Mean Comparisons of the Density and Moisture Content of the Evaluated Wood Species

\begin{tabular}{|c|c|c|c|c|}
\hline $\begin{array}{l}\text { Wood } \\
\text { Species }\end{array}$ & $\begin{array}{l}\text { Air-dry Density } \\
\qquad\left(\mathrm{g} / \mathrm{cm}^{3}\right)\end{array}$ & MC (\%) & $\begin{array}{c}\text { Volume } \\
\text { shrinkage } \\
\text { Coefficient (\%) }\end{array}$ & $\begin{array}{c}\text { Density at a MC } \\
\text { of } 12 \%\left(\mathrm{~g} / \mathrm{cm}^{3}\right)\end{array}$ \\
\hline Poplar & $0.45(9.23) \mathrm{D}$ & $8.64(2.52) \mathrm{C}$ & 39.62 & 0.46 \\
\hline Mahogany & $0.65(5.75) \mathrm{C}$ & $9.26(2.20) \mathrm{B}$ & 33.55 & 0.66 \\
\hline Ash & $0.74(2.54) \mathrm{A}$ & 9.69 (2.37) A & 54.28 & 0.75 \\
\hline Beech & $0.68(5.53) \mathrm{B}$ & $9.22(2.70) \mathrm{B}$ & 0.460 & 0.69 \\
\hline \multicolumn{5}{|c|}{$\begin{array}{l}\text { Note: the values in parenthesis are the coefficient of variance (COV) as a percentage; the } \\
\text { mean value in the same column not followed by a common upper letter is significantly } \\
\text { difference at the } 5 \% \text { significance level. }\end{array}$} \\
\hline
\end{tabular}

\section{Vibrational Characteristics}

Table 2 shows the typical outputted results via FFT. Figure $2 \mathrm{a}$ is the hammer force and time curve, Fig. 2b is the frequency response spectrum, as well as the ratio of acoustic pressure to hammer force, and Fig. 2c shows an acoustic attenuation curve, which is in accord with the exponential function. In addition, Fig. $2 \mathrm{~d}$ gives the coherence of the hammer force and acoustic pressure. The fundamental frequency $\left(F_{1}\right)$ can be obtained using the following methods: pick the frequency corresponding to the peak value shown in Fig. $2 \mathrm{~b}$, and then check Fig. 2c. If the coherence is close to 1 , then this frequency is the $F_{1}$.

Figure 3 shows the typical load and deflection curves of the four evaluated wood species, which indicated that the failure mode of mahogany was brittle fracture, while the other species were ductile fracture. The MOEs and MOR can be obtained using Eqs. 2 and 3 , respectively, and the lower and upper load limits were $300 \mathrm{~N}$ and $700 \mathrm{~N}$, respectively, so the $\Delta P$ was $400 \mathrm{~N}$. 

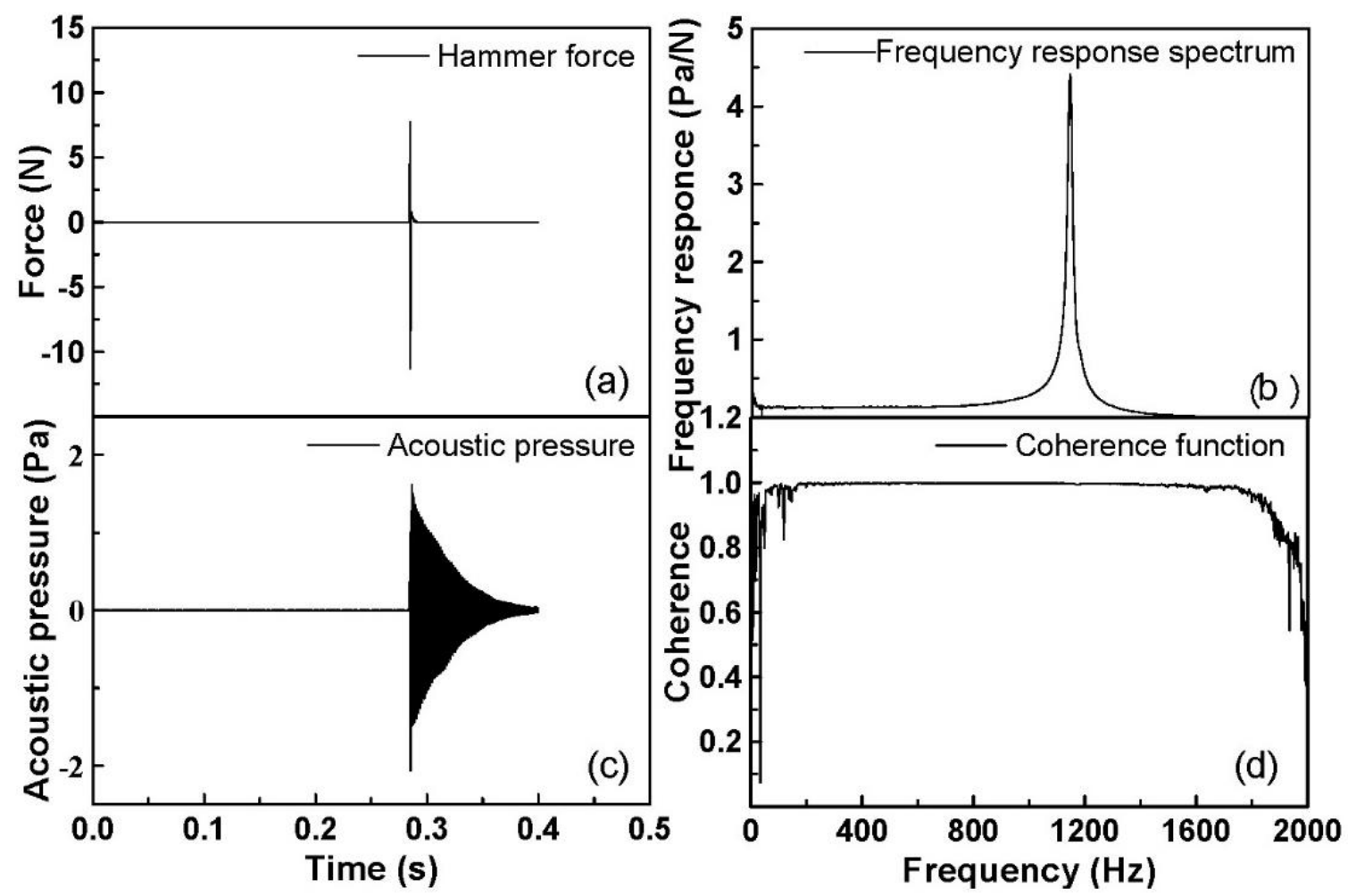

Fig. 2. Data output via FFT: (a) the hammer force; (b) the frequency response spectrum; (c) the acoustic pressure; and (d) the coherence between the hammer force and acoustic pressure

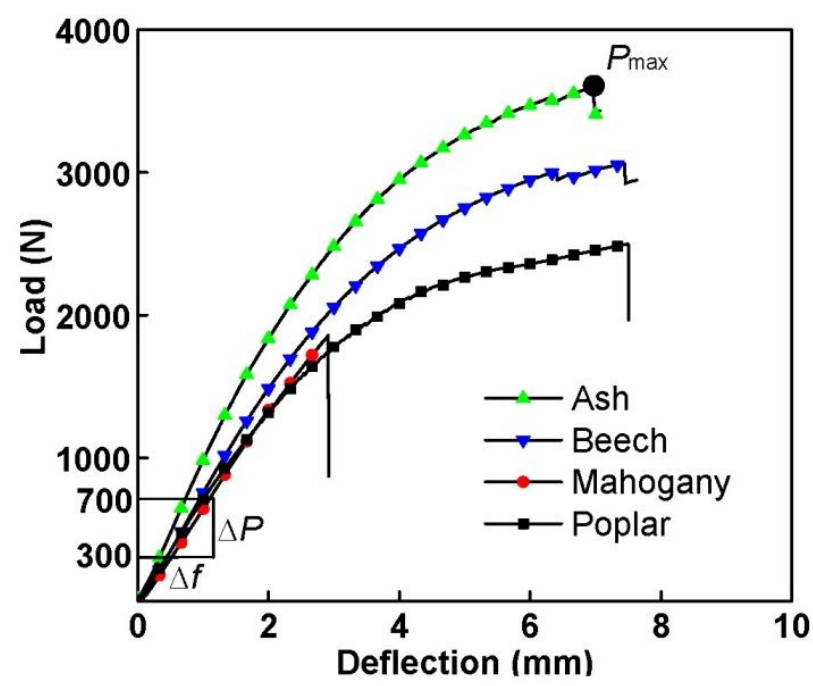

Fig. 3. Typical load-deflection curves under three-point bending

Table 2 shows the fundamental frequency, $\mathrm{MOE}_{\mathrm{d}}, \mathrm{MOE}_{\mathrm{s}}$, and MOR of the four evaluated wood species. The wood species had a significant effect on the $\mathrm{MOE}_{\mathrm{d}}$ and $\mathrm{MOE}_{\mathrm{s}}$, but the difference in these values for ash and beech was not significant. The effect of the striking direction on the $\mathrm{MOE}_{\mathrm{d}}$ of ash and beech wood was not significant. The $\mathrm{MOE}_{\mathrm{d}}$ values of all wood species were greater than their corresponding $\mathrm{MOE}_{\mathrm{s}}$ values (Yin et al. 2005; Jiang et al. 2008; Fu et al. 2021). For the MOR values of all evaluated wood species, the order from high to low was as follows: ash, beech, poplar, and mahogany. 
Table 2. Summaries of the Vibrational and Mechanical Properties of the Four Evaluated Wood Species

\begin{tabular}{|c|c|c|c|c|c|}
\hline Wood Species & Direction & $F_{1}(\mathrm{~Hz})$ & $\mathrm{MOE}_{d}(\mathrm{MPa})$ & MOEs (MPa) & MOR (MPa) \\
\hline Poplar & $\mathrm{n} / \mathrm{a}$ & $1147(5.0)$ & $11175(9.6) \mathrm{B}$ & 7118 (13) B & $82.5(14.2)$ \\
\hline Mahogany & $\mathrm{n} / \mathrm{a}$ & $838(6.0)$ & $8598(12) \mathrm{C}$ & 6399 & $59(20.7)$ \\
\hline \multirow{2}{*}{ Ash } & $\mathrm{R}$ & $1026(2.3)$ & 15789 (6.5) A & \multirow{2}{*}{$11192(11.5) \mathrm{A}$} & \multirow{2}{*}{$120.4(11.9)$} \\
\hline & $\mathrm{L}$ & $1048(2.4)$ & $15652(5.6) \mathrm{A}$ & & \\
\hline \multirow{2}{*}{ Beech } & $\mathrm{R}$ & $990(8.4)$ & $15204(20) \mathrm{A}$ & \multirow{2}{*}{10958 (16) A } & \multirow{2}{*}{$116.3(12.6)$} \\
\hline & $L$ & $1047(7.3)$ & $14444(16) \mathrm{A}$ & & \\
\hline
\end{tabular}

Note: $R$ and $L$ denote the radial and tangential surface of the wood sample, respectively; Values in parenthesis are the coefficient of variance $(\mathrm{COV})$ as a percentage; the mean value in the same column not followed by a common upper letter is significantly difference at the $5 \%$ significance level.

Concerning the above results, attention must be paid to the fact that the MOEd of poplar was greater than the $\mathrm{MOE}_{\mathrm{d}}$ of mahogany, but the density of mahogany was greater than the density poplar. According to Eq. 1 , the $\mathrm{MOE}_{\mathrm{d}}$ is positively proportional to the $F_{1}$ and density when the dimension of the sample is constant. Although the density of poplar was significantly less than the density of mahogany, the $F_{1}$ of poplar was significantly greater than the $F_{1}$ of mahogany. Therefore, further analysis is needed to determine the relationship between the density and the $F_{1}$.

Figure 4 shows the relationships between the $F_{1}$ and $\mathrm{MC}$ and the density. A previous study (Liu et al. 2005) reported a general method for applying FFT to measure the $\mathrm{MOE}_{\mathrm{d}}$ of various wood species, so all wood species can be regarded as a population sample with different densities and MCs. The fitting line and correlation coefficients showed that there were negative relationships between the $F_{1}$ and $\mathrm{MC}$, and previous studies also confirmed this point ( $\mathrm{Lu}$ et al. 2016; Cai et al. 2020). The $F_{1}$ decreased with the increase of wood density, even though these correlation coefficients were relatively lower, which resulted from the deviation of mahogany data from the population samples.
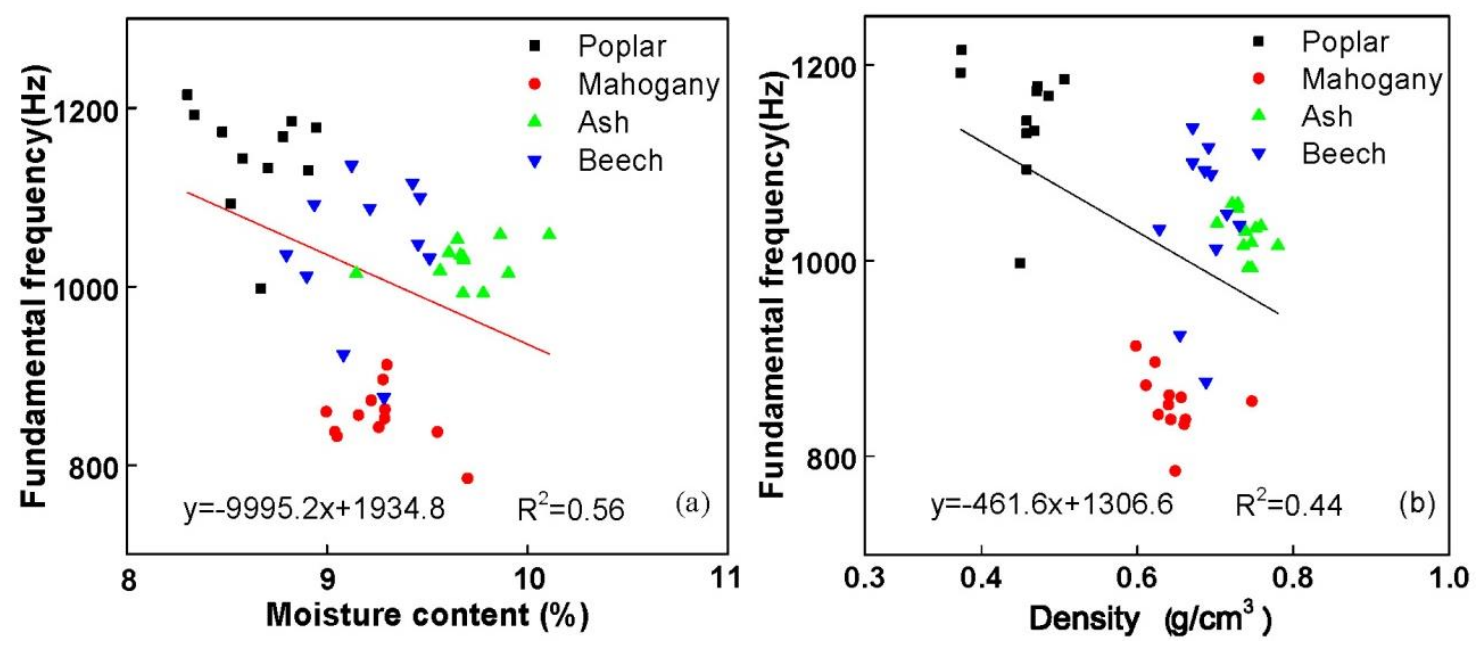

Fig. 4. Relationships between the fundamental frequency and the (a) moisture; and (b) density

Figure 5 shows the correlations between the $F_{1}$ and $\mathrm{MC}$ and the density using a color map. A rainbow band was generated with changes in the $\mathrm{MC}$ and density, apart from 
the region corresponding to mahogany circled in red. Figure 5 also shows that the $F_{1}$ decreased as the MC increased when density was a constant. However, when the MC was controlled, the $F_{1}$ decreased in a wave trend as the density increased. These trends also confirmed the results shown in Fig. 4.

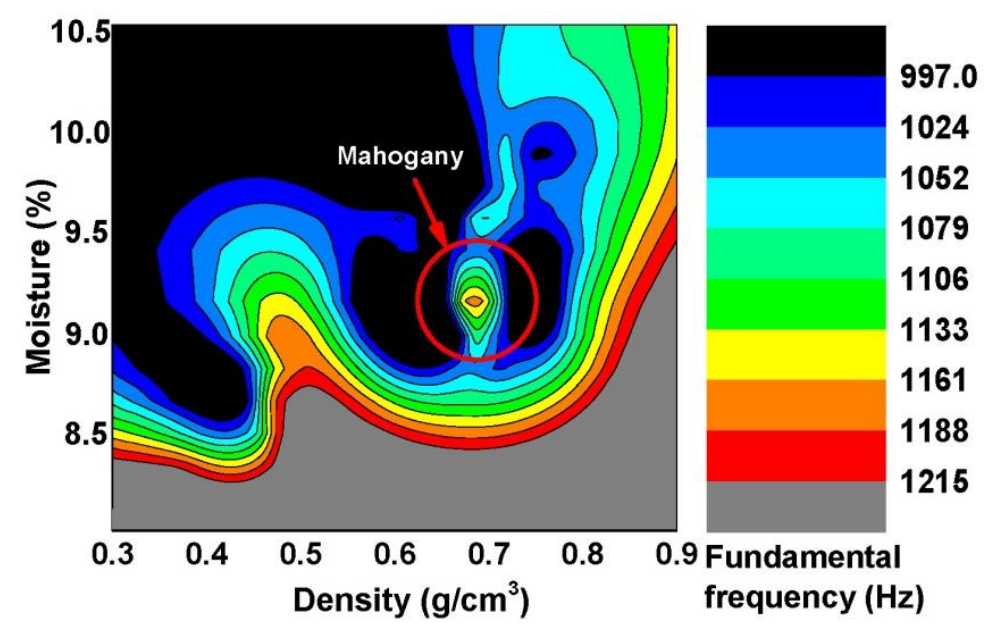

Fig. 5. Color map showing the relationship between the fundamental frequency and density and the moisture

These results suggest a deviation of the results for mahogany, relative to those of the other species. This may be due to the interlocking grain of mahogany in the longitudinal direction (Bergman et al. 2010). The other grains of the evaluated wood species in the longitudinal direction were straight (Fig. 6). In addition, this may be the reason why mahogany exhibited brittle fractures whereas the other species had ductile fractures. Figure 7 shows that the acoustic pressure attenuation curve of mahogany was remarkably different from the other three wood species. Specifically, the acoustic pressure attenuation curves of ash, beech and poplar decreased exponentially as time increased, while the acoustic pressure attenuation of mahogany decreased in a wave trend. This phenomenon may be used to judge the grain trend in the longitudinal direction of wood and provide new evidence for wood grading based on NDT.

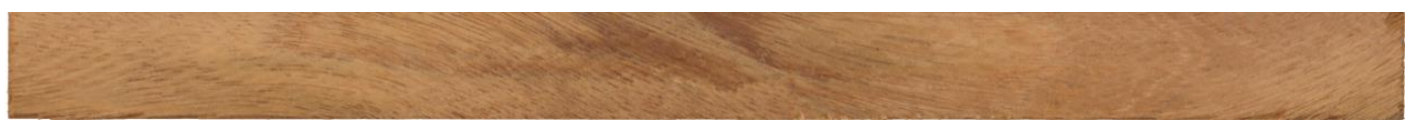

(a)

(b)

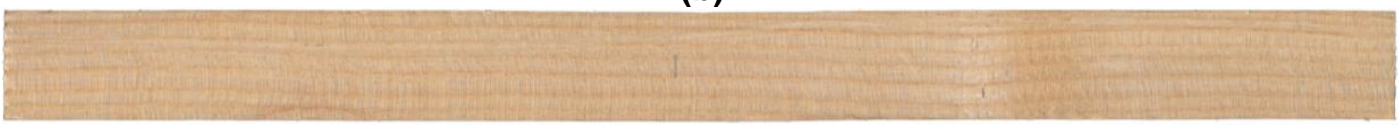

(c)

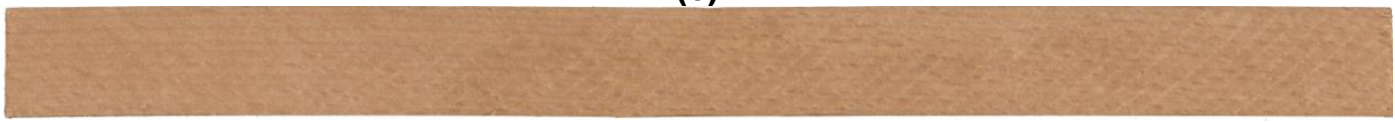

(d)

Fig. 6. Longitudinal grains of the wood samples: (a) mahogany; (b) poplar; (c) ash; and (d) beech 


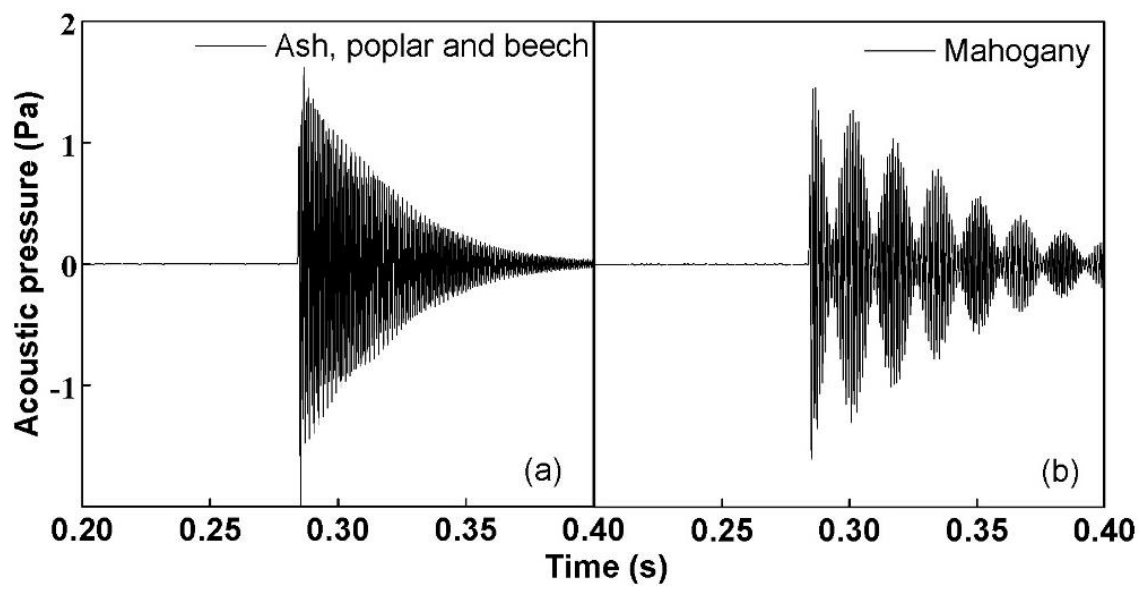

Fig. 7. Acoustic pressure attenuation curve of the evaluated wood species evaluated

In addition, the aim of this paper was to compare the vibrational characteristics of four wood species in air-dry condition or equilibration moisture content, so the moisture content was not adjusted. All above results shows that wood moisture content and wood density have interactive effects on wood fundamental frequency and MOEd. Wood moisture content and density also are the basic wood physical parameters which directly relate to the wood mechanical properties (Yin and Liu 2021). However, wood moisture content and density varies from one wood species to another one, even though in the same condition (Fu et al. 2021b; Yin and Liu 2021). Thus, finding another indicator to reflect the mechanical properties of wood is important. The results of this study showed that vibrational characteristics could be an effective alternative. In future work, the effects of actively controlling moisture content and density on vibration characteristics of different wood species will be studied.

\section{CONCLUSIONS}

The vibrational characteristics of four commonly used wood species in wood products were studied via the transverse vibration method. The following conclusions were drawn:

1. The effect of the wood species on the fundamental frequency $\left(F_{1}\right)$ and the dynamic modulus of elasticity $\left(\mathrm{MOE}_{\mathrm{d}}\right)$ were significant. Specifically, the order of these values, from high to low, was as follows: ash, beech, poplar, and mahogany. However, the difference between ash and beech was not significant.

2. The striking direction of the hammer had no significant effect on the $\mathrm{MOE}_{\mathrm{d}}$; specifically, it did not matter if the radial or tangential surface was struck, the MOE was always almost constant.

3. There were negative relationships between the $F_{1}$ and moisture content and the density when all wood species evaluated were regarded as a population sample.

4. The mechanical and acoustic behaviors of mahogany were remarkably different from the mechanical and acoustic behaviors of the other three evaluated wood species, which was likely due to its interlock grain in the longitudinal direction. 


\section{ACKNOWLEDGMENTS}

This study was partially supported by the Scientific Research Foundation of Nanjing Forestry University (GXL2019074) and partially supported by the Project from International Cooperation Joint Laboratory for Production, Education, Research and Application of Ecological Health Care on Home Furnishing.

\section{REFERENCES CITED}

ASTM D 6874 (2020). "Standard test methods for nondestructive evaluation of the stiffness of wood and wood-based materials using transverse vibration or stress wave propagation," ASTM International, West Conshohocken, PA.

Bergman, R., Cai, Z., Clausen, C. A., Dietenberger, M. A., Falk, R. H., Frihart, C. R., Glass, S. V., Hunt, C. G., Ibach, R. E., Kretschmann, D. E., et al. (2010). Wood Handbook: Wood as an Engineering Material (General Technical Report FPL-GTR190), U. S. Department of Agriculture, Forest Products Laboratory, Madison, WI.

Bi, J., Fu, Wang, Q., Wu, S., and Song, X. (2020). "Study on dynamic viscoelasticity of cork from Quercus variabilis," Journal of Forestry Engineering 5(3), 59-65.

Cai, C., Zhou, F., and Cai, J. (2020). "Bound water content and pore size distribution of thermally modified wood studied by NMR," Forests 11(12), 1279-1288. DOI: 10.3390/f11121279

Fu, W.-L., Guan, H.-Y., and Zhang, X.-Y. (2021a). "Verification and further study on method of measuring contact force between mortise and tenon joint," BioResources 16(1), 263-276. DOI: 10.15376/biores.16.1.263-276

Fu, W.-L., Guan, H.-Y., and Kei, S. (2021b). "Effects of moisture content and grain direction on the elastic properties of beech wood based on experiment and finite element method," Forests 12(5), 1-17. DOI: 10.3390/f12050610

GB/T 1931 (2009). "Method for determination of the moisture content of wood," Standardization Administration of China, Beijing, China.

GB/T 1933 (2009). "Method for determination of the density of wood," Standardization Administration of China, Beijing, China.

GB/T 1936.1 (2009). "Method of testing in bending strength of wood," Standardization Administration of China, Beijing, China.

GB/T 1936.2 (2009). "Method for determination of the modulus of elasticity in static bending of wood," Standardization Administration of China, Beijing, China.

Ilic, J. (2003). "Dynamic MOE of 55 species using small wood beams," European Journal of Wood and Wood Products 61(3), 167-172. DOI: 10.1007/s00107-003$0367-8$

ISO 16978 (2003). "Wood-based panels - Determination of modulus of elasticity in bending and of bending strength," International Organization for Standardization, Geneva, Switzerland.

Jiang, J., Lv, J., Ren, H., Luo, X., Long, C., and Guo, W. (2008). "Evaluation of modulus of elasticity for dimension lumber by three nondestructive techniques," Journal of Zhejiang Forestry College 25(3), 277-281.

Ju, S., Li, X., Luo, T., and Li, M. (2019). "Anisotropic propagation of acoustic emission signal on surface of Pinus massoniana Lamb. glulam," Journal of Forestry Engineering 4(2), 48-53. 
Katalin, K., Markus, D., and Peter, N. (2014). "Determination of dynamic elastic moduli and shear moduli of aged wood by means of ultrasonic devices," Materials and Structures 47(6), 925-936. DOI: 10.1617/s11527-013-0103-8

Kawamoto, S., and Williams, R. S. (2002) Acoustic Emission and Acousto-Ultrasonic Techniques for Wood and Wood-Based Composites - A review (Report No. FPLGTR-134), U. S. Department of Agriculture, Forest Products Laboratory, Madison, WI.

Li, X., Deng, T., Wang, M., Ju, S., Li, X., and Li, M. (2020). “Linear positioning algorithm improvement of wood acoustic emission source based on wavelet and signal," Journal of Forestry Engineering 5(3), 138-143.

Liu, X. Y., Lv, M. Q., Liu, M., and Lv, J. F. (2019). "Repeated humidity cycling's effect on physical properties of three kinds of wood-based panels," BioResources 14(4), 9444-9453. DOI: 10.15376/biores.14.4.9444-9453

Liu, Z. B., Liu, Y. X., Yu, H. P., and Yuan, J. Q. (2005). "Research on the dynamic modulus of elasticity measurement of lumber," Scientia Silvae Sinicae 41(6), 11261131.

Lu, X., He, Q., Yao, Y., Zhang, H., Lu, K., and Ju, Z. (2016). “The study of natural frequency and its impact factors of two types of international common wood for table tennis racket blade," Journal of Forestry Engineering 1(1), 16-20. DOI: 10.13360/j.issn.2096-1359.2016.01.003

Lv, X., Miao, Y., Lin, B., Zhang, Y., Gao, Y., Qian, L., and Liu, Z. (2018). "Study on acoustic vibration performance of wood-carbon fiber composite materials with different laying patterns," Journal of Forestry Engineering 3(4), 96-101.

Mohammad, R. A., and Mohsen, F. (2017). "A semi-empirical relation between static and dynamic elastic modulus," Journal of Petroleum Science and Engineering 157, 359363. DOI: $10.1016 /$ j.petrol.2017.06.055

Olaoye, K., Okon-Akan, O. A., Adegoke, O., and Bobadoye, A. O. (2020). "Correlation among physico-acoustic properties of Boscia angustifolia and Albizia adianthifolia wood," Forest Products Journal 70(4), 396-402. DOI: 10.13073/FPJ-D-20-00033

Olaoye, K., and Okon-Akan, O. A. (2020). "Estimation of modulus of elasticity of Boscia angustifolia wood using longitudinal vibration acoustic method," International Wood Products Journal 11(1), 122-128. DOI: 10.1080/20426445.2020.1738118

Tao, X., Han, J., Xu, W., and Feng Y. (2019). "Effect of spruce grain angle on acoustic vibration properties of piano soundboard," China Wood Industry 33(4), 14-17.

Tu, J., Zhao, D., and Zhao, J. (2020). "Experimental study for determining method of cracking load of wooden beams with LT crack," Journal of Forestry Engineering $5(3), 149-154$.

Turkot, C. G., Seale, R. D., Entsminger, E. D., França, F. J. N., and Shmulsky, R. (2020). "Nondestructive evaluation of red oak and white oak species," Forest Products Journal 70(3), 370-377. DOI: 10.13073/FPJ-D-20-00015

Xu, W., Fang, X., Han, J., Wu, Z., and Zhang, J. (2020). "Effect of coating thickness on sound absorption property of four wood species commonly used for piano soundboards," Wood and Fiber Sciences 52(1), 28-43. DOI: 10.22382/wfs-2020-004

Yang, L., and Liu, H. (2021). "Study of the collapse and recovery of Eucalyptus urophydis during conventional kiln drying," European Journal of Wood and Wood Products 79 (1), 129-137. DOI: 10.1007/s00107-020-01614-w 
Yin, Y., Li, Y., Li, J., Wang, Z., Ma, Q., Liu, Q., Zhao, M., Wang, D., Sun, Z., Li, F. (2005). "Evaluating static bending elastic properties of full-size lumbers by using transverse vibration method," Journal of Beijing Forestry University 27(5), 107-110.

Yin, Q., and Liu, H. (2021). "Drying stress and strain of wood: A review," Applied Sciences-Basel 11(11), 5023. DOI: 10.3390/app11115023

Zhang, L., Tiemann, A, Zhang T., Gauthier, T., Hsu, K., Mahamid, M., Moniruzzaman, P. K., and Ozevin, D. (2021). "Nondestructive assessment of cross-laminated timber using non-contact transverse vibration and ultrasonic testing," European Journal of Wood and Wood Products 79(2), 335-347. DOI: 10.1007/s00107-020-01644-4

Zhao, F., Tang, T., Hou, S., and Fu, Y. (2020). "Preparation and synergistic effect of chitosan/sodium phytate/MgO nanoparticle fire-retardant coatings on wood substrate through layer-by-layer self-assembly," Coatings 10(9), 1-9. DOI: 10.3390/coatings 10090848

Zhao, Z., Sun, S., Wu, D., Zhang, M., Huang, C., Umemura, K., and Yong, Q. (2019). "Synthesis and characterization of sucrose and ammonium dihydrogen phosphate (SADP) adhesive for plywood," Polymers 11(12), 1-16. DOI: 10.3390/polym11121909

Zhou, C., Yu, M., and Zhou, T. (2018). "Experimental study on three-dimensional shape mapping of complex furniture," EURASIP Journal on Image and Video Processing (9), 89. DOI: 10.1186/s13640-018-0311-9

Zhou, N., Zhang, G., Huang, D., Jiang, S., and Zhang, Q. (2019). "Examination of dynamic characteristics of new bamboo structure by impact hammer test," Journal of Forestry Engineering 4(2), 54-60.

Article submitted: July 29, 2021; Peer review completed: August 10, 2021; Revised version received and accepted: August 21, 2021; Published: September 9, 2021.

DOI: 10.15376/biores.16.4.7101-7111 